\title{
O processo de Gênese Instrumental do GeoGebra 3D em alunos do Ensino Médio Normal/Magistério
}

\author{
Débora Bussolotto - PPGEMAT /UFRGS - debibussolotto@gmail.com \\ Márcia Rodrigues Notare - PPGEMAT /UFRGS - marcia.notare@ufrgs.br
}

Resumo: Neste artigo descreve-se um estudo realizado com alunos do $3^{\circ}$ ano do Ensino Médio Normal/Magistério de uma instituição pública na cidade de Nova Prata/RS, com o objetivo de analisar o processo de gênese instrumental pessoal do GeoGebra 3D. Com base na teoria da Gênese Instrumental de Rabardel (1995), analisou-se a constituição de esquemas de utilização do GeoGebra, desenvolvidos por alunos participantes de uma oficina cujo foco foi a construção de peças virtuais do jogo Brincando de Engenheiro. $\mathrm{O}$ estudo, de caráter qualitativo, buscou identificar esquemas que foram desenvolvidos e/ou evocados na construção das peças, em paralelo com a análise da compreensão de conceitos matemáticos inerentes às construções propostas. Os resultados do estudo apontam para a identificação do processo de gênese instrumental do GeoGebra 3D desses estudantes em um movimento de transformação de artefato em instrumento, por meio da constituição de esquemas de utilização que foram elaborados durante a oficina.

Palavras-chave: Gênese Instrumental; GeoGebra; Brincando de Engenheiro; Esquemas.

\section{The process of GeoGebra 3D Instrumental Genesis in students of Normal Scholl Degree}

Abstract: In this article it is described a study that was performed with students from a Public high school institution in Normal School degree in the city of Nova Prata - Rio Grande do Sul. The goal was to analyze the process of instrumental creation or origin of the GeoGebra 3D. According to the Instrumental Genesis of Rabardel theory (1995), it was analyzed the formation of uses schemes of the GeoGebra. It was developed by students that were participating in a workshop, which it was focusing on the construction of virtual pieces from a game called Playing Engineer ("Brincando de Engenheiro"). The study, which had a qualitative methodology, look for identification schemes and were developed and used on the construction of the pieces, together with the analyses of the mathematic concepts related to what was proposed to the students. The study results aim to the identification of the Instrumental Genesis of the GeoGebra 3D that occured with these students in a way of transforming a device into instrument through the formation of the use of schemes that were done during the workshop performed by the students.

Keywords: Instrumental Genesis; GeoGebra; "Brincando de Engenheiro"; Schemes.

\section{Introdução}

A ascensão do uso de tecnologias digitais traz a possibilidade de sair do dueto papel-quadro, para a utilização de softwares que tragam dinamicidade a construções geométricas. O software GeoGebra, com seus recursos de régua e compasso virtuais, que viabilizam construções de objetos geométricos dinâmicos, vem apoiar o estudo das geometrias plana e espacial (Notare e Basso, 2016). A exploração e análise de construções de estudantes podem revelar conceitos geométricos que foram utilizados, assim como conceitos que ainda não foram compreendidos (Notare e Basso, 2017). A análise das construções mostra-se reveladora no estudo do processo de aprendizagem de geometria. Por outro lado, a Teoria da Gênese Instrumental (Rabardel, 1995) permite 
analisar o caminho percorrido por um sujeito na transformação de um artefato em instrumento, revelando o processo de apropriação do recurso tecnológico por esse sujeito. Este processo é formado pela elaboração de esquemas de utilização, os quais Rabardel (1995) distingue em dois níveis, denominados como esquemas de uso e esquemas de ação instrumentada.

A proposta aqui descrita analisa o processo de gênese instrumental do GeoGebra 3D de alunos em atividades de construção de peças virtuais do jogo Brincando de Engenheiro. Os sujeitos da pesquisa, alunos da $3^{\mathrm{a}}$ série do Ensino Médio Normal/Magistério, participaram de uma oficina na qual foram apresentados ao software GeoGebra e instigados a realizar as construções geométricas das peças.

\section{A Teoria da Gênese Instrumental}

A teoria da gênese instrumental de Rabardel (1995) estuda os esquemas desenvolvidos por um sujeito em processo de transformação de um artefato em instrumento. Para Rabardel (1995), um artefato não é um instrumento acabado, ele carece de usos e atividades que o constituam como um instrumento funcional para atingir metas estabelecidas pelo usuário. Neste processo, deve-se considerar o sujeito, sendo ele o operador da ação, o objeto, sobre o qual a ação é dirigida, e o instrumento, sendo este o mediador da relação entre sujeito e objeto.

$\mathrm{O}$ artefato é caracterizado por um objeto físico ou simbólico (por exemplo: calculadora, martelo, software). Já o instrumento se constrói a partir de duas componentes: a componente artefato, que é desenvolvida pelo sujeito, e uma componente psicológica (Trouche, 2004). A componente psicológica refere-se à constituição de esquemas. Os esquemas são elementos estáveis e estruturados na atividade e nas ações do usuário. Eles adaptam-se ao longo do tempo, emergindo da necessidade de sua utilização em novas tarefas, como também novos esquemas surgem e passam a ser agregados ao artefato e são necessários para a realização de determinada tarefa.

Os esquemas relacionados ao uso do artefato são definidos por Rabardel (1995) como esquemas de utilização e ocorrem em dois planos: no plano secundário, estão relacionados à descoberta e gestão das propriedades e características do artefato; e no plano primário, relacionados ao objeto da atividade, no qual o artefato é um meio de efetivação da tarefa. Os dois planos possibilitam distinguir esquemas de uso de esquemas de ação instrumentada. Os esquemas de uso estão direcionados à utilização do artefato a partir do conhecimento das suas propriedades. Estão em um nível de esquemas elementares que não são decomponíveis em unidades menores. Já os esquemas de ação instrumentada são direcionados à realização de uma tarefa, que visa modificar objeto. São esquemas que tratam da totalidade da ação, do ato global, e que incorporam os esquemas de uso. Conforme Trouche (2004), para constituir determinado esquema de ação instrumentada, o sujeito necessitará desenvolver esquemas de uso. Para a execução de uma tarefa "é necessário o domínio de um esquema formado por uma totalidade articulada e simultânea de esquemas de uso - este é o esquema de ação instrumentada" (Stormowski, 2015, p.53). Ambos os esquemas (de uso e de ação instrumentada), constituem um esquema de utilização, sendo possível identificá-los apenas ao término da tarefa proposta, pois ambos visam a resolução da mesma.

Os esquemas de utilização são aplicados de diferentes maneiras e contextos, pois visam resolver uma tarefa proposta. Porém, um mesmo esquema de utilização pode ser utilizado com a finalidade de desvendar o artefato como também de explorar um objeto fazendo uso do artefato. 
A origem e constituição do instrumento dependem de esquemas de utilização e de artefatos que serão instrumentalizados e instrumentados pelo sujeito, sendo os esquemas distintos em cada sujeito. Assim, ao considerar o artefato, com suas potencialidades e limitações, e os esquemas de utilização a fim de serem utilizados na direção de distintos objetos, constituem o instrumento. Sua evolução dependerá de novos esquemas que serão agregados ou de esquemas que serão reformulados, devido ao progresso do artefato.

Este desenvolvimento decorre da necessidade do sujeito na realização de novas tarefas. As elaborações instrumentais são direcionadas ao próprio sujeito, constituindo o processo de instrumentação, e direcionadas ao artefato, constituindo o processo de instrumentalização. O processo de instrumentalização permite ao sujeito identificar as funções e as limitações do artefato para, posteriormente, personalizá-lo, relacionando-se à descoberta de propriedades do artefato. É um processo guiado na direção sujeito $\rightarrow$ objeto. A instrumentação é o processo no qual os esquemas surgem e são adequados, a fim de que o artefato imprima sua marca no sujeito. Este processo guia-se na direção objeto $\rightarrow$ sujeito e está relacionado à elaboração de esquemas.

No que diz respeito às funções do artefato, inicialmente estas são instrumentalizadas para solucionar um determinado problema, para, em um segundo momento, serem acomodadas como propriedades. Ambas etapas caracterizam o processo de instrumentalização. Ao passo que novas propriedades surgem, temos esquemas constituindo novos instrumentos e esquemas novos são acomodados, constituindo o processo de instrumentação. Ambos processos estão conectados, tornando-se impossível sua distinção. Conforme Notare e Basso (2017), o sujeito explora as funções do artefato, selecionando-as para realização de sua tarefa por meio da instrumentalização. Porém, somente no processo de instrumentação o artefato deixará marcas no sujeito.

Na Figura 1 é possível observar um esquema que ilustra o processo da gênese instrumental.

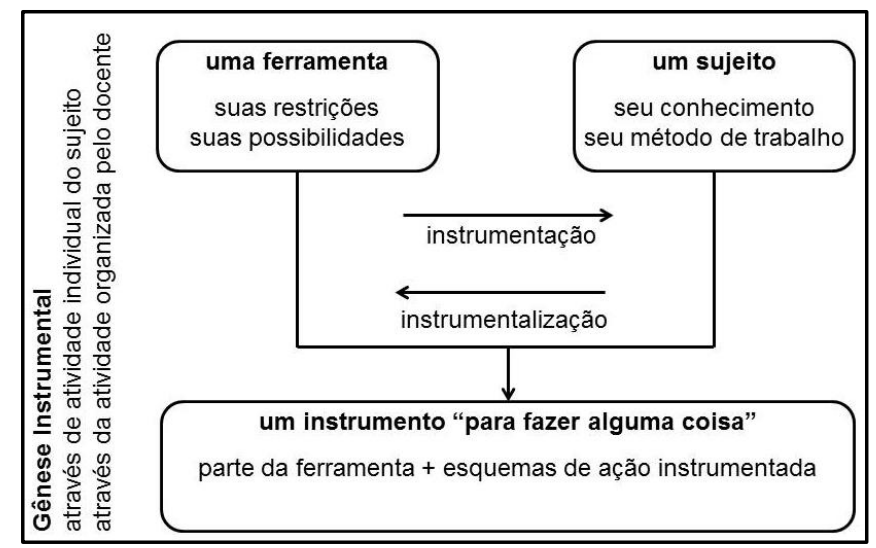

Figura 1 - Esquema ilustrativo do processo de Gênese Instrumental Fonte: traduzido de Trouche (2004)

A gênese instrumental resultará em um instrumento constituído inicialmente por um artefato e que foi modificado durante a trajetória do sujeito por esquemas de utilização.

Esta teoria, com base no estudo do processo de transformação de artefato em instrumento, mediado pela elaboração de esquemas, torna-se um aporte teórico para o estudo de tecnologias digitais em Matemática, em específico no estudo da geometria dinâmica. Assim sendo, nesse trabalho, o software disponibilizado ao aluno e objeto de estudo, o GeoGebra, é inicialmente um artefato que, ao ser explorado a fim de construir 
objetos, provocará a constituição de esquemas de utilização, que o transformarão em um instrumento funcional para os alunos.

\section{GeoGebra como instrumento em atividades de geometria dinâmica}

O GeoGebra, software escolhido para esse estudo, apresenta duas janelas de construção: uma em 2D e outra em 3D. Os recursos disponibilizados pelo software possibilitam construções geométricas dinâmicas a partir de régua e compasso virtuais. Mas, para que as construções sejam dinâmicas e estáveis, propriedades matemáticas devem ser impostas na construção e se manterem sob a ação do movimento.

A janela de visualização 3D permite construções de objetos geométricos dinâmicos espaciais. Muitas das ferramentas utilizadas na janela de visualização 3D são também disponíveis na janela 2D; entretanto, novas ferramentas, específicas das figuras espaciais, são disponibilizadas. O processo de transformação do GeoGebra 3D em um instrumento funcional para a construção de figuras espaciais dinâmicas e estáveis passa pela constituição de diversos esquemas de utilização, tanto referentes ao uso do artefato em si (descoberta de propriedades do artefato), quanto referentes ao uso das ferramentas matemáticas que devem ser utilizadas nas construções de modo a manter estáveis as propriedades do objeto geométrico que está sendo construído. A análise de elaboração e uso de esquemas pelos estudantes, sujeitos da pesquisa, é foco das seções a seguir. Vamos analisar os esquemas de utilização dos sujeitos, por meio da análise de suas construções, observando o processo de gênese instrumental do GeoGebra 3D.

\section{Procedimentos Metodológicos}

Para analisar o processo de gênese instrumental do GeoGebra 3D, foi desenvolvida uma oficina para alunos da $3^{\text {a }}$ série do Ensino Médio Normal/Magistério de uma instituição pública do município de Nova Prata. A oficina contou com cinco alunos participantes e foi distribuída em cinco encontros. A metodologia de pesquisa utilizada foi o Estudo de Caso, com base em Ponte (2006), pois segundo o autor, ela possibilita o estudo em profundidade das particularidades, considerando cada situação única e especial. O caso estudado foi caracterizado por estudantes Ensino Médio Normal/Magistério, futuros professores da Educação Básica - séries iniciais, que não conheciam o software GeoGebra (portanto, ainda um artefato para eles).

Os dados analisados são constituídos por registros escritos pelos alunos, por observações e registros do pesquisador, por gravações em vídeo e áudio e pelos arquivos do GeoGebra elaborados pelos alunos.

A oficina teve como foco principal a construção dinâmica de peças do jogo Brincando de Engenheiro (Figura 2).

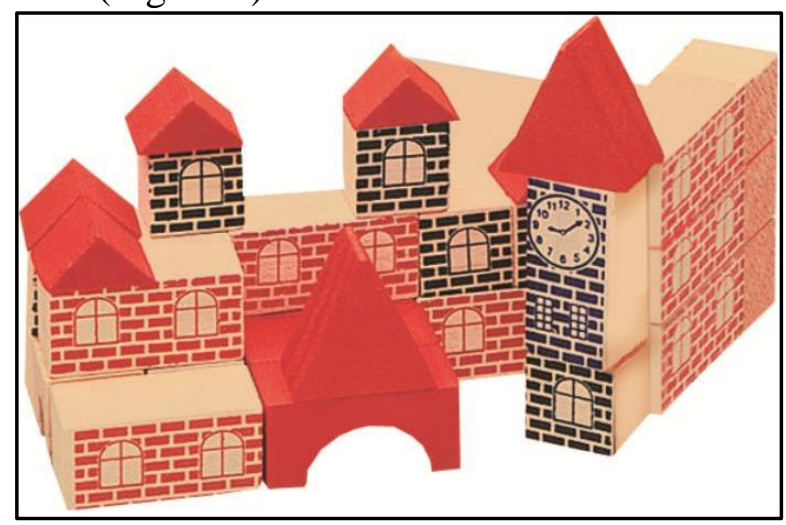

Figura 2 - Peças do jogo "Brincando de Engenheiro".

Fonte: www.xalingo.com.br/brinquedos/pt/produtos/educativos/5276.5/brincando-de-engenheiro-ii (2018). 
A seção a seguir descreve e analisa o processo de construção das peças virtuais do jogo pelos sujeitos, à luz da teoria da gênese instrumental.

\section{Descrição e Análise da Gênese Instrumental}

$\mathrm{O}$ encontro inicial foi dedicado à exploração do GeoGebra 2D, para que os alunos explorassem os recursos do software e compreendessem os princípios básicos de construção em ambiente dinâmico. Nesse encontro inicial, os estudantes elaboraram os primeiros esquemas de utilização do GeoGebra, dando início ao processo de transformação de artefato em instrumento.

Nesse artigo, serão analisadas as construções de três peças do jogo Brincando de Engenheiro, caracterizando um recorte do experimento realizado. Ambas construções deveriam partir de um segmento inicial, sendo base para todas as construções, de modo que as proporções entre as arestas de todas as peças fossem mantidas, já que, depois de construídas as peças, os estudantes deveriam realizar uma construção mais complexa utilizando várias peças. As peças analisadas são o cubo e os prismas de bases quadrangular, retangular e triangular menor.

As construções deveriam ser dinâmicas e estáveis, ou seja, as construções deveriam levar em conta as propriedades geométricas de cada peça. Fazendo uso de conceitos de geometria plana e espacial e dos recursos disponibilizados pelo software, os alunos construíram esquemas de uso e esquemas de ação instrumentada que lhes permitiram concretizar a construção. Os alunos precisaram desenvolver esquemas de uso para utilização do GeoGebra, sendo que este ainda era desconhecido por eles. Ainda foi necessária a constituição de esquemas de utilização para a construção das peças, apoiados em conceitos matemáticos. Observou-se que as construções dos estudantes foram semelhantes e, dessa forma, selecionamos as peças de um dos estudantes da oficina, denominado Aluno1, para representar esse processo.

\subsection{Construção do Cubo}

As peças físicas do jogo Brincando de Engenheiro foram disponibilizadas aos alunos para que pudessem manuseá-las, a fim de identificarem relações geométricas. $\mathrm{Na}$ Figura 3 pode-se observar a peça Cubo, escolhida para construção inicial.

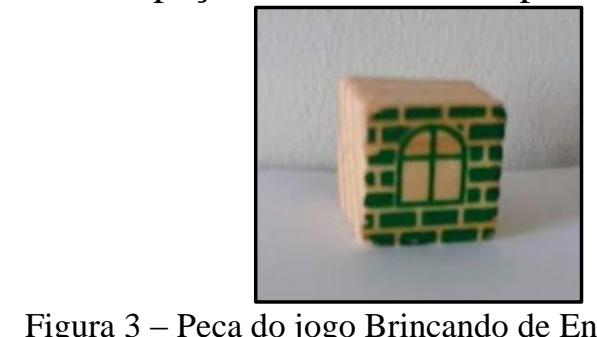

Figura 3 - Peça do jogo Brincando de Engenheiro: Cubo

Fonte: acervo pessoal

O segmento inicial que foi construído estabeleceu a medida das arestas do cubo. O primeiro obstáculo encontrado pelo Aluno1 na construção do cubo foi sobre como utilizar essa medida para construir as demais arestas. Levando-se em conta que os alunos construíram quadrados no plano anteriormente, situação na qual foi necessário desenvolver o seguinte esquema de ação instrumentada: círculos podem ser utilizados como compassos virtuais para transportar medidas de segmentos, o Aluno1 poderia evocar esse esquema e ampliá-lo para esse novo contexto de janela de visualização 3D. Entretanto, um esquema só pode ser considerado esquema se for um elemento estável e estruturado na atividade e nas ações do sujeito e, nesse caso, o Aluno1 ainda não tinha ampliado e generalizado a ação, de modo a repeti-la em uma nova situação. Após 
algumas discussões, o Aluno1 percebeu que poderia utilizar, no espaço, uma esfera, cujo raio seria determinado pelo segmento inicial, e que indicaria as medidas das arestas do cubo. Nesse momento, a partir da necessidade da utilização do recurso esfera para transportar medida de segmentos, o Aluno1 desenvolve um novo esquema de uso, que precisa ser agregado a sua estrutura.

Dando continuidade à construção, o Aluno1 percebeu a necessidade de construção de retas perpendiculares às arestas da base passando pelos seus vértices (esquema já constituído na construção do quadrado no plano), a fim de determinar a perpendicularidade entre as arestas da base do cubo.

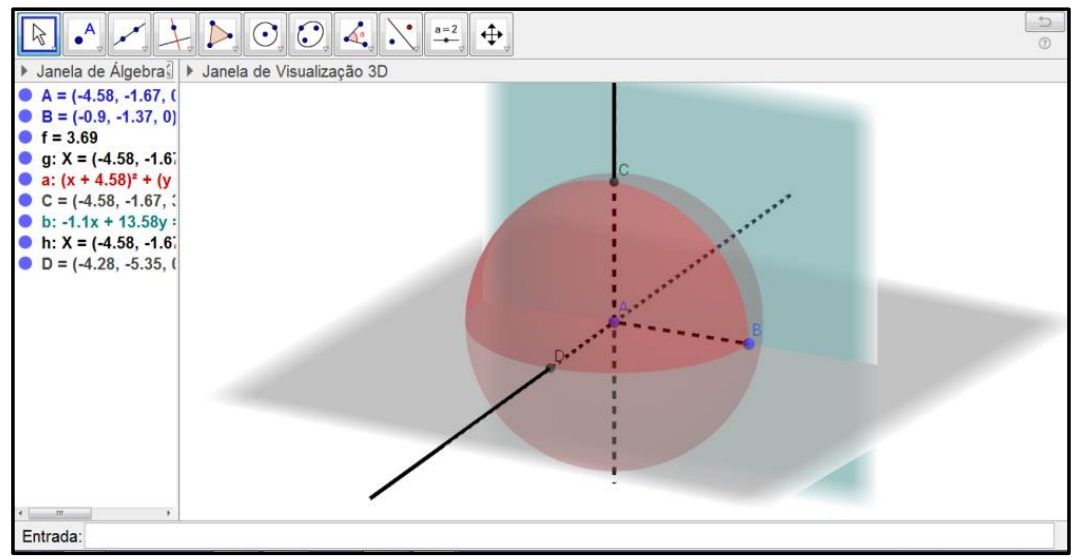

Figura 4 - Construção de um plano pelo Aluno1.

Fonte: acervo pessoal

A Figura 4 ilustra a reta que contém o segmento $\overline{A C}$, que foi construída a partir da ferramenta "Retas Perpendiculares". Porém, para a construção da reta que contém o segmento $\overline{A D}$, o Aluno1 precisou desenvolver um novo esquema de uso que necessitava da construção de um novo plano, já que, no espaço, é necessário indicar a qual plano a reta construída será perpendicular. Uma vez construídas as retas perpendiculares, o Aluno1 pôde determinar as demais arestas da base do cubo, utilizando as ferramentas "Retas Paralelas" ou "Retas perpendiculares".

Estabelecida a base do cubo e sua altura, o próximo passo era sua construção, fazendo uso do recurso "Prisma". A partir da análise acima, percebe-se que a construção do cubo desencadeou a elaboração de diferentes esquemas de uso do GeoGebra, os quais constituem um esquema de ação instrumentada em sua totalidade, que visava a efetivação da tarefa proposta (construção da peça Cubo). A Figura 5 apresenta o resultado final obtido na construção pelo Aluno1, com os objetos geométricos auxiliares ainda evidentes.

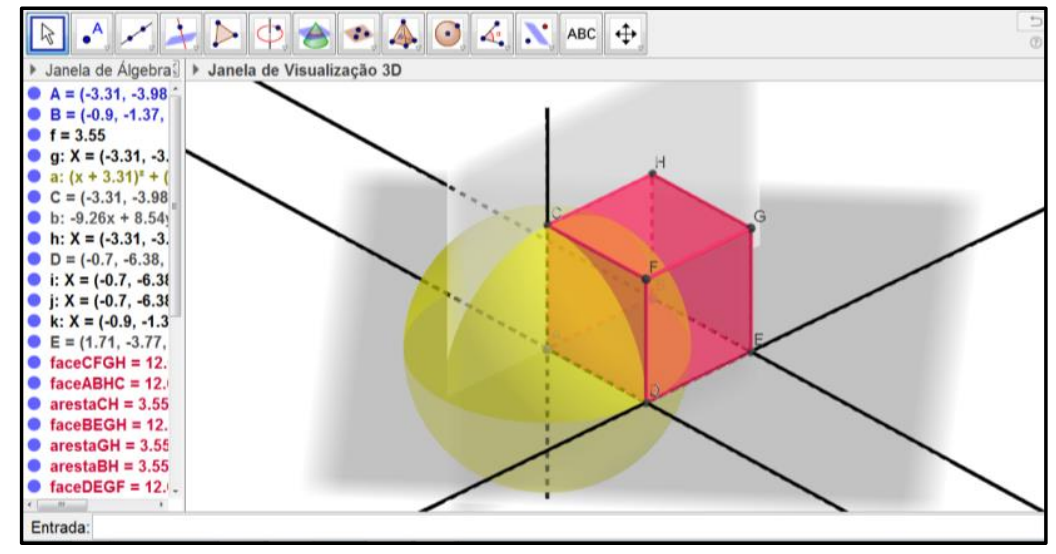

Figura 5 - Construção da peça "Cubo" pelo Aluno1.

Fonte: acervo pessoal 
Finalizada a construção da peça, os alunos deveriam, por meio do recurso "Nova Ferramenta", criar a ferramenta da peça Cubo, a fim de utilizá-la futuramente em construções mais complexas, compostas por diferentes peças do jogo. A utilização deste recurso foi orientada pelo pesquisador. O Aluno1 precisou desenvolver um novo esquema de utilização para utilizar o recurso com sucesso e definir sua peça Cubo como objeto a ser utilizado posteriormente.

\subsection{Construção dos prismas de base quadrangular e retangular}

Após a construção do cubo, as peças físicas do jogo foram disponibilizadas novamente para que os alunos "escolhessem" a próxima peça a ser construída. Após exploração das mesmas, em discussão realizada com o grande grupo, os alunos decidiram construir as peças das "janelinhas", que aqui serão nomeadas como prisma de base quadrangular e prisma de base retangular. Na Figura 6 é possível observar os dois prismas selecionados para construção.

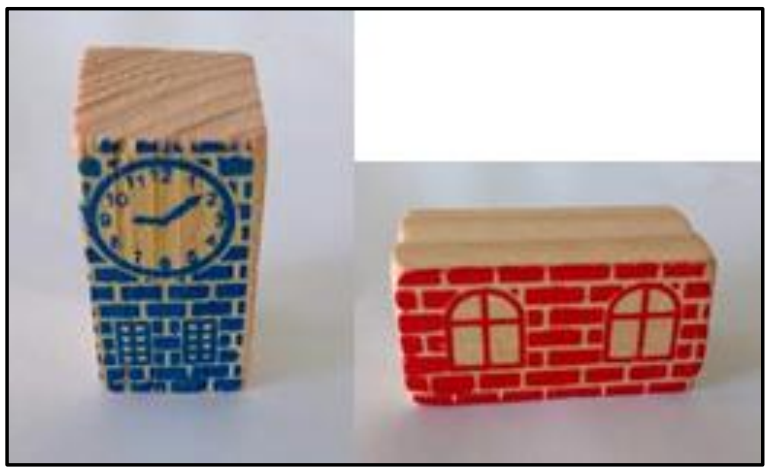

Figura 6 - Peças do jogo Brincando de Engenheiro: prisma de base quadrangular e prisma de base retangular

Fonte: acervo pessoal

O manuseio das peças físicas permitiu que os alunos estabelecessem comparações com o cubo. Observaram que o prisma de base quadrangular possui a mesma base que do cubo, porém, com altura sendo o dobro da aresta do cubo. De maneira semelhante, os estudantes destacaram que, no prisma de base retangular, "caberiam" dois cubos lado a lado e a altura seria igual à medida da aresta do cubo.

Os elementos geométricos utilizados na construção do cubo poderiam ser utilizados na construção destas novas peças. Como os estudantes utilizaram a construção do cubo para dar início à nova construção, esquemas já existentes puderam ser evocados, como os utilizados para a construção do quadrado da base e das arestas laterais. Porém, a determinação de arestas cuja medida seria o dobro da aresta do cubo desencadeou um novo processo de exploração do GeoGebra e a construção de novos esquemas.

O prisma obtido pelo Aluno1 pode ser visualizado na Figura 7. Analisando a construção do prisma de base quadrangular do Aluno1, percebe-se que sua estratégia foi utilizar o recurso esfera para determinar a altura do prisma, tomando como raio da esfera o comprimento da aresta do cubo (segmento $\overline{A C}$ ) e como centro o vértice $C$ do cubo. Desta forma, o diâmetro da esfera, que corresponde ao dobro do raio, determinou a altura do prisma, que corresponde ao dobro da aresta da base. 

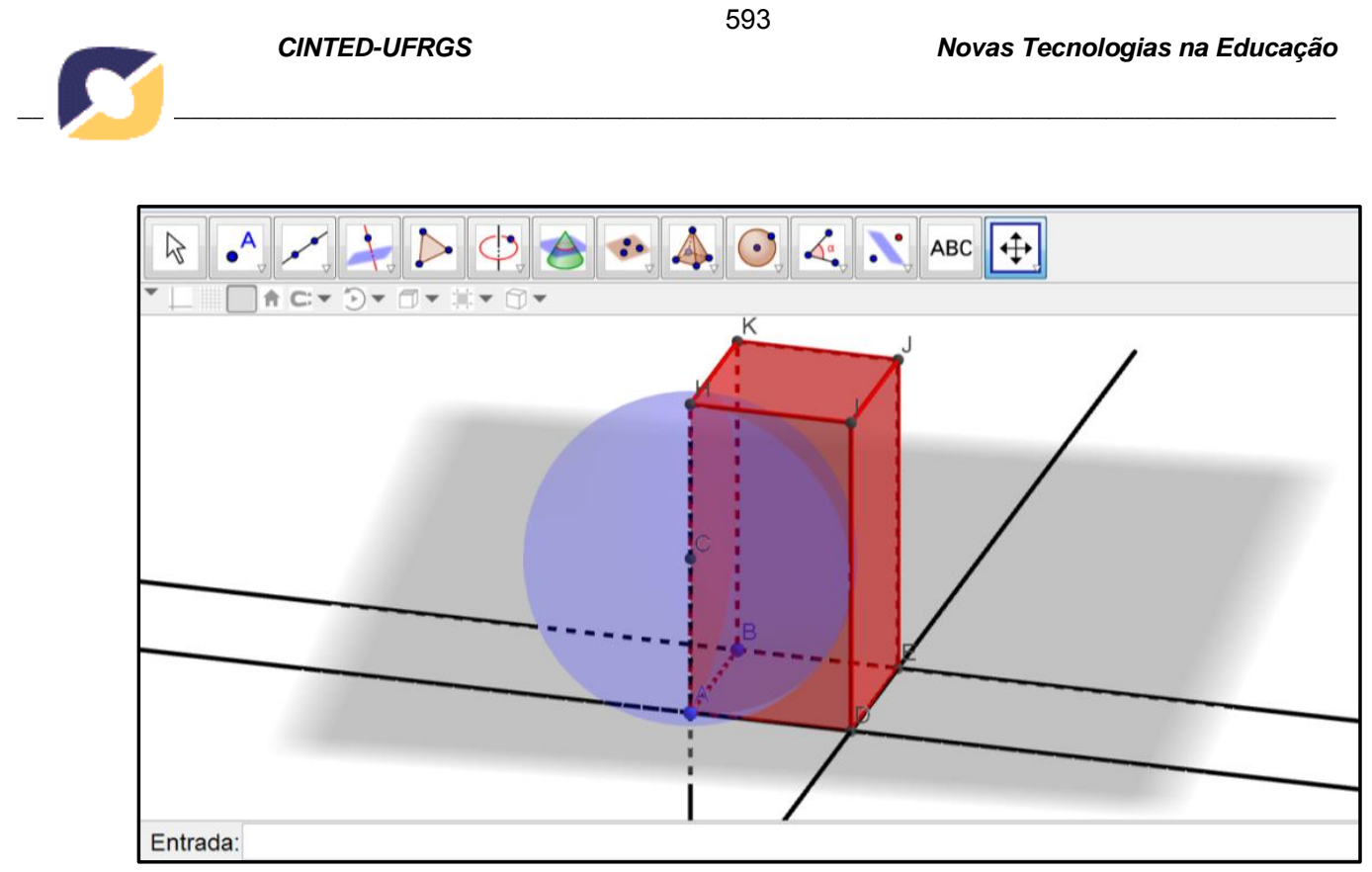

Figura 7 - Construção do prisma de base quadrangular pelo Aluno1

Fonte: acervo pessoal

Percebe-se aqui autonomia e desenvoltura na construção, o que revela o emprego de esquemas de utilização que o Aluno1 já havia elaborado durante a construção do cubo. A construção do quadrado da base e a determinação das arestas laterais passaram a constituir-se como elementos estáveis e estruturados nas ações do Aluno1. É possível destacar a utilização de uma sequência de esquemas de uso que permitiu a construção dos prismas. Essa composição de esquemas de uso determinam a totalidade da ação de construir o prisma, ou seja, um esquema de ação instrumentada, composto pelos novos esquemas e pelos esquemas já existentes, que se reorganizaram e estruturaram no ato global. Esse processo evidencia a gênese instrumental vivenciada pelo Aluno1: o software GeoGebra, que incialmente era um artefato, passa a transformar-se, por meio dos esquemas elaborados, em um instrumento de construções geométricas e, consequentemente, de aprendizagem de geometria.

\subsection{Construção do prisma de base triangular}

Essa peça foi a última a ser construída pelo Aluno1. A peça foi denominada pelos alunos como "telhadinhos", mas aqui a trataremos como prisma de base triangular menor. Na Figura 8 é possível observar as peças físicas que foram disponibilizadas aos alunos para manuseio e observação das relações que poderiam ser estabelecidas com as construções anteriores.

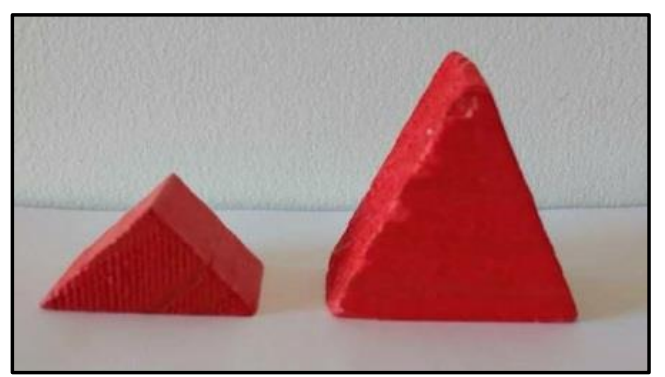

Figura 8 - Peça do jogo Brincando de Engenheiro: Prismas de base triangular Fonte: acervo pessoal

Após manuseio das peças, em discussão realizada individualmente, os alunos foram instigados a observar relações existentes com as construções anteriores. $\mathrm{O}$ Aluno1 destacou que o telhadinho menor teria medidas de arestas que se assemelhavam à base de construção do cubo. A nomenclatura "prisma de base triangular" não foi 
ressaltada inicialmente na discussão, a fim de que os alunos viessem a observar as relações existentes para a construção do mesmo. Cabe destacar que, no jogo, esse prisma, por cumprir a função de telhado, é usualmente disposto com uma das faces laterais sendo a base do telhado (conforme disposto na Figura 8).

Após algumas discussões referentes às relações matemáticas existentes, o Aluno1 observou que a altura do telhadinho, ou altura do triângulo, representava metade da altura do cubo. Para realizar essa construção no GeoGebra, foi necessário desenvolver um novo esquema de uso, para construir um ponto no centro de uma das faces do cubo, possibilitando encontrar e limitar a altura do telhadinho. A partir da exploração do GeoGebra, buscando descobrir novas propriedades do instrumento que desse conta de solucionar essa construção, o Aluno1 identificou o recurso "Ponto Médio ou Centro", determinando o ponto no centro da diagonal de uma das faces do cubo e desenvolvendo um novo esquema de uso do GeoGebra. O próximo passo seria, a partir de supostos esquemas já obtidos nas construções anteriores, construir o prisma. Porém, ao utilizar o recurso Prisma, foi preciso ampliar o esquema previamente elaborado, a fim de compreender que a base do prisma não era a base do cubo, mas sim o triângulo determinado em uma das faces laterais. A nova configuração da figura e uma posição diferente da usual (bases paralelas ao "chão") provocou um desequilíbrio no Aluno1, fazendo com que seu esquema não funcionasse nessa situação. Após vivenciar o problema, o Aluno1 modificou o esquema, reconhecendo a importância de identificar corretamente a base do prisma para que a construção ficasse como esperado. Na Figura 9 é possível observar os elementos geométricos utilizados na construção final do telhadinho.

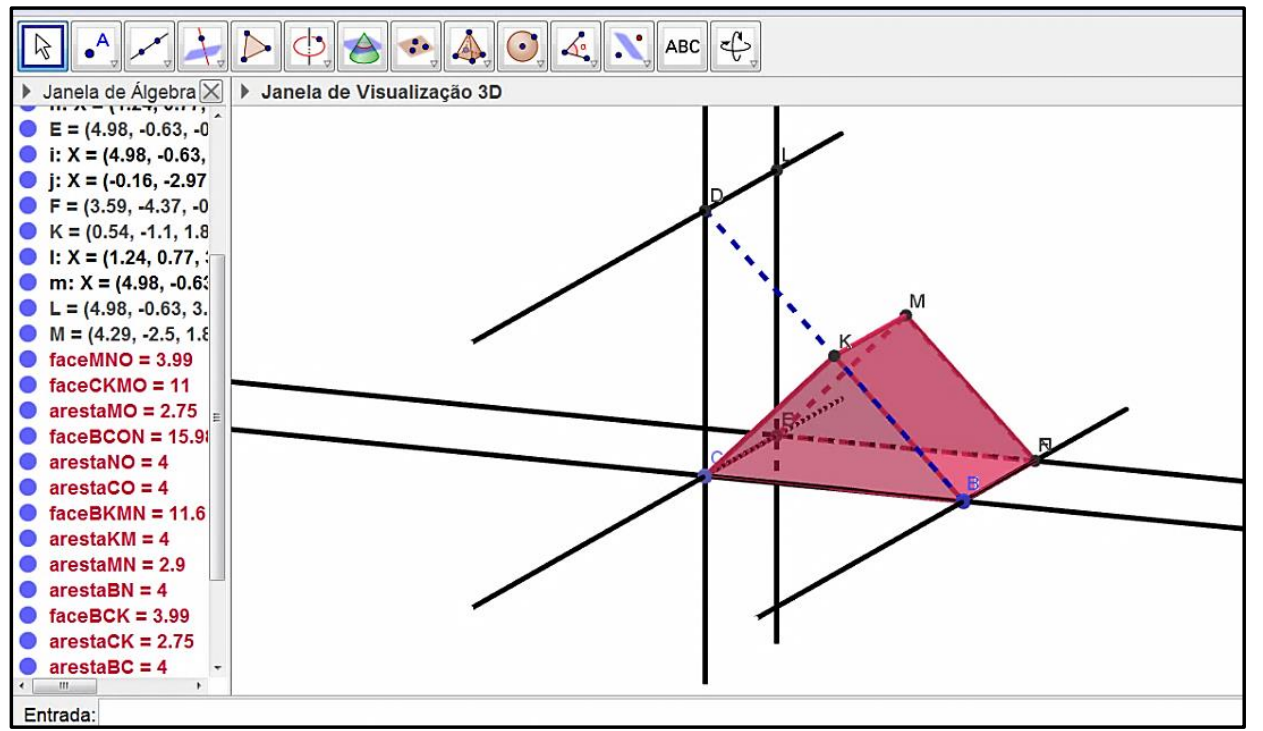

Figura 9 - Construção do prisma de base triangular menor "telhadinho" pelo Aluno1 Fonte: acervo pessoal

A partir da análise das construções das peças realizadas pelo Aluno1, foi possível acompanhar o processo de apropriação do GeoGebra 3D, que, antes da oficina, era desconhecido por ele (portanto um artefato). Ao longo das construções realizadas, o Aluno1 foi elaborando esquemas de utilização que foram transformando o artefato em instrumento.

\section{Considerações Finais}

Nesse trabalho, apresentamos um estudo sobre o processo de gênese instrumental do GeoGebra 3D por alunos da $3^{\text {a }}$ série do Ensino Médio Normal/ 
Magistério. Os alunos participantes da pesquisa puderam, a partir da oficina e da construção das peças do jogo Brincando de Engenheiro, dar início ao processo de gênese instrumental do GeoGebra, desenvolvendo esquemas de uso e esquemas de ação instrumentada, em um processo de transformação de artefato em instrumento.

A utilização de tecnologias digitais em uma sala de aula de alunos na Modalidade Normal agregada à compreensão de conceitos de Geometria Plana e Espacial, transformando o software em um instrumento didático a ser utilizado nas futuras salas de aula dos normalistas. A pesquisa teve continuidade, analisando propostas de utilização do GeoGebra elaborada pelos estudantes, futuros professores, durante a oficina, nas quais analisou-se também o início de um processo de gênese profissional, em que os estudantes reconheceram no GeoGebra um instrumento com potencial para a aprendizagem de geometria. Sabemos que a elaboração do instrumento é individual para cada sujeito e, portanto, trouxemos aqui o estudo de um caso, que ilustra um processo de exploração do artefato e de elaboração de esquemas.

\section{Referências}

ABAR, C. A. A. P.; ALENCAR, S. V. A Gênese Instrumental na Interação com o GeoGebra: uma proposta para a formação continuada de professores de Matemática. Bolema, v. 27, n. 46, p. 349, 2013.

DA PONTE, J. P. Estudos de caso em educação matemática. Boletim de Educação Matemática, v. 19, n. 25, 2006.

NOTARE, M. R.; BASSO, M. V. A. Geometria dinâmica 3D: novas perspectivas para o pensamento espacial. RENOTE: revista novas tecnologias na educação. Vol. 14, n. 2 (2016), 10 p., 2016.

NOTARE, M. R.; BASSO, M. V. de A. Gênese Instrumental do GeoGebra na Formação de Professores. Zetetiké, Campinas, SP, v.25, n.2, maio/ago.2017, p.324344.

RABARDEL, P. (1995). Les hommes et les technologies: une approche cognitive des instruments contemporains. Paris: Armand Colin.

TROUCHE, L. Managing the complexity of human/machine interactions in computerized learning environments: Guiding students' command process through instrumental orchestrations. International Journal of Computers for mathematical learning, v. 9, n. 3, p. 281, 2004.

STORMOWSKI, V. Formação de professores de matemática para o uso de tecnologia: uma experiência com o GeoGebra na modalidade EAD, no Estado do Rio Grande do Sul: UFRGS, 2015. 226p. Tese de Doutorado. 